\title{
hMEF2C Gene Encodes Skeletal Muscle- and Brain-Specific Transcription Factors
}

\author{
JOHN C. MCDERMOTT, ${ }^{1}$ M. CRISTINA CARDOSO ${ }^{1}$ YIE-TEH YU,${ }^{1} \dagger$ VICENTE ANDRES, ${ }^{1}$ \\ DANA LEIFER, ${ }^{2}$ DIMITRI KRAINC, ${ }^{2}$ STUART A. LIPTON, ${ }^{2}$ \\ AND BERNARDO NADAL-GINARD ${ }^{1 *}$ \\ Howard Hughes Medical Institute and Department of Cardiology, Children's Hospital, Department of \\ Cellular and Molecular Physiology and Department of Pediatrics, Harvard Medical School, \\ Boston, Massachusetts $02115,{ }^{1}$ and Department of Neurology, Children's Hospital \\ and Harvard Medical School, Boston, Massachusetts $02114^{2}$
}

Received 24 November 1992/Returned for modification 8 January 1993/Accepted 18 January 1993

\begin{abstract}
The myocyte enhancer-binding factor 2 (MEF2) site is an essential element of many muscle-specific enhancers and promoters that binds nuclear proteins from muscle and brain. Recently, we have cloned a family of MEF2 transcription factors produced by two genes that, at the mRNA level, are broadly expressed and produce tissue-specific isoforms by posttranscriptional processes (Y.-T. Yu, R. E. Breitbart, L. B. Smoot, Y. Lee, V. Mahdavi, and B. Nadal-Ginard, Genes Dev. 6:1783-1798, 1992). Here, we report the isolation and functional characterization of cDNA clones encoding four MEF2 factors derived from a separate gene that we have named hMEF2C. In contrast to those of the previously reported genes, the transcripts of the hMEF2C gene are restricted to skeletal muscle and brain. One of the alternate exons is exclusively present in brain transcripts. The products of this gene have DNA-binding and trans-activating activities indistinguishable from those of the previously reported MEF2 factors. The hMEF2C gene is induced late during myogenic differentiation, and its expression is limited to a subset of cortical neurons. The potential targets for this transcription factor in a subset of neurons are not known at this time. The strict tissue-specific pattern of expression of hMEF2C in comparison with the more ubiquitous expression of other MEF2 genes suggests a different mode of regulation and a potentially important role of hMEF2C factors in myogenesis and neurogenesis.
\end{abstract}

Diverse cellular signals are involved in the induction of cell-type-specific genes that commit multipotent precursor cell lines to specific cell lineages. During the last decade, identification of factors responsible for the commitment of cells to a particular developmental fate has been one of the most productive aspects of developmental biology. The formation of skeletal muscle has proven to be a powerful model for the study of the mechanisms involved in both the production of cellular lineages as well as the establishment of the differentiated phenotype in vertebrates. Identification of the family of basic helix-loop-helix (bHLH) myogenic regulators (the MyoD family) as factors which can induce the myogenic program in a number of mesodermally derived cells has advanced our understanding of this process. The demonstration that they function as sequence-specific transcription factors, binding at the E-box present in many muscle enhancers and promoters, has become a paradigm for the analysis of cell determination and differentiation (16, $38,50)$. However, despite the elegance and persuasiveness of the myogenesis model based on the MyoD family, it is clear that this family of regulators can neither be the exclusive myogenic determinants nor be wholly responsible for muscle-specific gene transcription. This is so because not all muscle-specific genes contain E-boxes, and even when they are present, they are not necessarily required for musclespecific gene regulation $(4-7,9,18,21,25,31,36,49,53)$. In addition, many genes induced by MyoD in skeletal muscle

\footnotetext{
* Corresponding author.

† Present address: Division of Cardiology, Department of Medicine, School of Medicine, Vanderbilt University, Nashville, TN 37232-2170.
}

are also expressed in cardiac and, in some cases, smooth muscle, where the bHLH myogenic regulators have not been found and, therefore, unrelated lineage-determining genes must operate.

Several families of transcription factors, in addition to the MyoD family of regulators, which mediate lineage determination and differentiation, such as the homeodomain (13) and MADS-box proteins (52), have been found to be expressed in muscle tissue. These factors have been proven to mediate lineage determination and differentiation in other systems and could provide new insights on the molecular mechanisms of myogenesis. In particular, the known homeotic function of MADS-box proteins in plants $(11,26)$, together with their cooperative interaction with homeodomain proteins $(23,48)$, identifies them as candidates for evolutionarily conserved determinants of cell lineage. These interactions reveal a molecular strategy which through combinatorial mechanisms could generate a plethora of discrete signals necessary for the specification of a large number of different cell types by a limited number of factors.

Recently, a new family of MADS-box transcription factors named the myocyte enhancer factor $2(\mathrm{MEF} 2)$ genes have been identified (52). The MEF2 activity was originally characterized as an activity in skeletal muscle nuclear extracts that binds sequences in a number of muscle-specific enhancers and promoters with the consensus $(\mathrm{C} / \mathrm{T}) \mathrm{T}(\mathrm{A} / \mathrm{T})(\mathrm{A} /$ T)AAATA(A/G) $(14,22)$. Deletion analyses demonstrated that this sequence plays a fundamental role in musclespecific gene expression $(9,18,21,24,35,36,53)$. By using a consensus MEF2 DNA-binding site to probe a cDNA expression library from human skeletal muscle, several cDNA clones encoding the MEF 2 activity have been iso- 
lated in our laboratory (52). The cDNAs originally isolated are the products of two different genes that, through alternative splicing, encode several different proteins. Each of these proteins exhibited DNA-binding and trans-activation effects characteristic of the endogenous MEF2 activity. Interestingly, RNAs from these two genes are detected in all tissues and cell types examined so far, in sharp contrast to the tissue-specific restriction of the MEF2 activity, which is limited to the skeletal, cardiac, smooth muscle, and, perhaps, the nervous systems. Antibodies raised against these proteins showed them to be restricted to the cell types that exhibit MEF2 activity and indicate that posttranscriptional mechanisms, including alternative pre-mRNA splicing, are responsible for the tissue-specific expression of MEF2 activity from these two genes (52). The effect of the antibodies on the mobility of DNA-protein complexes demonstrated that the cloned cDNAs did not encode all of the MEF2 activity present in muscle and brain extracts.

We now report the isolation and characterization of cDNA clones encoding new members of the MEF2 family of transcription factors from a single gene which we have labelled $\mathrm{hMEF} 2 \mathrm{C}$. In contrast to the other MEF2 genes already reported, this gene is expressed in a tissue-specific manner and is restricted to skeletal muscle and brain. The products of the hMEF2C gene are very active transcription factors with a DNA-binding specificity indistinguishable from that of the MEF2 factors previously reported (52). Immunocytochemical analyses demonstrate that these factors are induced during myogenesis and, therefore, might be intrinsically involved in muscle formation. Interestingly, one of the alternatively spliced isoforms is produced exclusively in the brain and is limited to a subset of neurons.

\section{MATERIALS AND METHODS}

cDNA library screening. An adult human skeletal muscle cDNA library was screened with standard procedures. In brief, approximately $1.5 \times 10^{6}$ recombinant phage from the amplified lambda gt10 library were screened with randomprimed ${ }^{32}$ P-labelled cDNA (380-bp NsiI-NdeI fragment) from MEF2 (52) that had a specific activity of $1 \times 10^{9}$ $\mathrm{cpm} / \mu \mathrm{g}$ of DNA. Hybridization was carried out at $37^{\circ} \mathrm{C}$ in $25 \%$ formamide $-5 \times \mathrm{SSC}(1 \times \mathrm{SSC}$ is $0.15 \mathrm{M} \mathrm{NaCl}$ plus 0.015 $M$ sodium citrate) $-5 \times$ Denhardt's reagent- $1 \%$ sodium dodecyl sulfate (SDS) $-10-\mathrm{mg} / \mathrm{ml}$ calf thymus DNA to which $1 \times$ $10^{6} \mathrm{cpm}$ of radioactive probe per $\mathrm{ml}$ was added. The hybridized filters were washed twice for $30 \mathrm{~min}$ in $2 \times \mathrm{SSC}-0.5 \%$ SDS at room temperature and then for $30 \mathrm{~min}$ at $37^{\circ} \mathrm{C}$. Several rounds of screening were carried out to ensure plaque purification. All inserts were subcloned into pGEM $7 z F(+)$. Clones were sequenced with an automated sequencing system (Applied Biosystems, Foster City, Calif.) by using a modified dideoxy chain termination method. Multiple sequence runs on both strands were performed. Computer analysis of the nucleic acid and protein sequences was carried out with the University of Wisconsin Genetics Computer Group sequence analysis software package and the Blast network service of the National Center for Biotechnology Information (17).

Plasmids and transfections. For in vitro transcription, translation, and sequencing, the cloned hMEF2C cDNAs (amino acids [aa] 1 to 435 ) were subcloned into pGEM7z $\mathrm{f}(+$ ) vectors (Promega Corp., Madison, Wis.). For expression, the cDNAs (aa 1 to 435) were subcloned into pMT2 vector (27). The embryonic myosin heavy-chain promoter (MHCemb) chloramphenicol acetyltransferase (CAT) con- struct consisted of two copies of the muscle creatine kinase (MCK) MEF2 sites inserted in a concatemerized orientation at the -102 position of the MHCemb promoter in plasmid PE102 CAT (52). The oligonucleotide binding sites were also cloned into the HindIII site of p8TKCAT (49) and at position -109 of the simian virus 40 early promoter (A10). Transient transfection assays were carried out as previously described (52). Briefly, HeLa cells were grown to $\sim 60 \%$ confluence and transfected with the various DNA expression constructs by calcium-phosphate coprecipitation. The cells were glycerol shocked after $18 \mathrm{~h}$ and harvested $48 \mathrm{~h}$ later. Each plate of cells was transfected with the following DNAs: $10 \mu \mathrm{g}$ of the appropriate CAT reporter construct, $5 \mu \mathrm{g}$ of the pMT2hMEF $2 C$ construct or the pMT2 vector alone, and $3 \mu \mathrm{g}$ of the pSV $\beta$-gal, which served as an internal control for the transfection efficiency. For the COS cell transfections, $20 \mu \mathrm{g}$ of the pMT2 expression construct was used. Cell extracts were prepared and CAT activity was determined by previously published procedures (52).

In vitro transcription and translation. For in vitro translation, hMEF2C-pGEM 7zF(+) constructs were linearized with either BamHI or PstI for the full-length cDNA-encoded protein (aa 1 to 435) and truncated translation products, respectively. The resulting RNA was translated in vitro with a rabbit reticulocyte lysate according to the manufacturer's suggested conditions (Promega). The in vitro translation products were analyzed by the incorporation of $\left.{ }^{35} \mathrm{~S}\right] \mathrm{methio-}$ nine, and a 3- $\mu \mathrm{l}$ aliquot was electrophoresed on an SDS-12\% polyacrylamide gel. After the proteins were resolved, the gel was exposed to Enlightning (DuPont) for $30 \mathrm{~min}$, dried, and autoradiographed.

DNA-binding assays. The DNA-binding assays were carried out as described by $\mathrm{Yu}$ et al. (52) with minor modifications. Complementary oligodeoxyribonucleotides were synthesized with an Applied Biosystems synthesizer. The gelretardation assay and preparation of cell extracts were carried out as previously described (52). For the DNAbinding assays with the in vitro-translated hMEF2C, the incubation reaction contained $1.5 \mu \mathrm{l}$ of the translated reticulocyte lysate, $0.2 \mathrm{ng}$ of probe, $0.45 \mu \mathrm{g}$ of poly $(\mathrm{dI}-\mathrm{dC})$, and $100 \mathrm{ng}$ of single-stranded oligonucleotide. The bound fraction and the free probe were electrophoresed on a $5 \%$ polyacrylamide gel (acrylamide-bis, $29: 1$ ) at $4^{\circ} \mathrm{C}$. The core nucleotide sequences of probes and competitor DNAs used in the binding assays were as follows:

$\begin{array}{ll}\text { MEF2, } & \text { 5'-CGCTCTAAAAATAACCCT-3' } \\ \text { MEF2mt1, } & \text { 5'-CGCTCTAAGGCTAACCCT-3' } \\ \text { MEF2mt4, } & \text { '-CGCTCTATAAATAACCCT-3' } \\ \text { MEF2mt6, } & \text { 5'-CGCTCTAAACATAACCCT-3' } \\ \text { CArG, } & \text { 5'-GGGGACCAAATAAGGCAA-3' }\end{array}$

Nucleotides in underlined print conform to the consensus sequence of the MEF2 site $(14,42)$.

RNA isolation and analysis. Total RNAs were prepared from mouse tissues and cells in culture by the guanidinium thiocyanate-phenol-chloroform extraction method (10). Poly $(\mathrm{A})^{+}$RNAs were purified in batch with oligo(dT) cellulose (type 3; Collaborative Research). The adult human tissue mRNA blot ( $2 \mu \mathrm{g}$ per lane) was obtained from Clontech (Palo Alto, Calif.). Blots were hybridized in $1 \mathrm{M} \mathrm{NaCl}-50$ $\mathrm{mM}$ Tris- $\mathrm{HCl}$ (pH 7.5)-1\% SDS-10-mg/ml calf thymus DNA-10\% dextran sulfate-50\% formamide with $1 \times 10^{6} \mathrm{cpm}$ of probe per $\mathrm{ml}$ at $42^{\circ} \mathrm{C}$. The blots were washed at progressively increasing stringencies up to $0.1 \times$ SSC-0.1\% SDS at $54^{\circ} \mathrm{C}$. 
PCR scanning. Poly $(\mathrm{A})^{+}$RNA was isolated from various tissue sources as described above. First-strand cDNA synthesis was performed with oligo(dT) as primer. The reaction medium contained $10 \mathrm{mM}$ Tris, $50 \mathrm{mM} \mathrm{KCl}, 2.5 \mathrm{mM} \mathrm{MgCl}_{2}$, 100 pmol of the primer, and $1 \mu \mathrm{g}$ of mRNA. After heating at $95^{\circ} \mathrm{C}$ for $2 \mathrm{~min}$ and cooling on ice, $10 \mathrm{U}$ of RNase inhibitor (Pharmacia) and $200 \mathrm{U}$ of reverse transcriptase were added, and the reaction was incubated at $37^{\circ} \mathrm{C}$ for $1 \mathrm{~h}$. Reverse transcriptase reaction product $(1.5 \mu \mathrm{l})$ was used as a template in a PCR with primers (P1 and P2) which amplify a large segment of the gene. The product of the initial reaction was then used as a template for the amplification of the alternate exons. Various combinations of primers flanking the known alternately spliced regions in the cDNAs were used to determine the presence or absence of these exons in the tissue-specific cDNA pools. Taq polymerase $(2.5 \mathrm{U})$ was added to a standard PCR mixture. The conditions for the PCR were 25 cycles of $94^{\circ} \mathrm{C}$ for $1.5 \mathrm{~min}, 65^{\circ} \mathrm{C}$ for $2 \mathrm{~min}$, and $72^{\circ} \mathrm{C}$ for $3 \mathrm{~min}$. The primer coordinates (from the sequence in Fig. 1A) were primer 1 , nucleotides (nt) 818 to 838 ; primer 2 , nt 1848 to 1866 ; primer 3 , nt 1427 to 1446 ; primer 4 , nt 1590 to 1611 ; primer 5 , nt 1636 to 1656 ; primer 6 , nt 1696 to 1716 ; and primer 7, nt 1837 to 1860 .

PCR amplification of the $3^{\prime}$ end of hMEF2C. The cloned cDNAs from the original library screening were not full length (extending to nt 1966, 93 nt from the $3^{\prime}$ end). We isolated the missing $3^{\prime}$ end from another skeletal muscle library. The strategy used for these experiments was to first amplify the copy number of the unknown region in the library by using a one-sided PCR with a gene-specific primer located towards the 3 ' end of the hMEF2C cDNA (primer 3 in Fig. 4, nt 1427 to 1446 ) with a lambda GT10 cDNA library as a template (conditions were $95^{\circ} \mathrm{C}$ for $1.5 \mathrm{~min}, 50^{\circ} \mathrm{C}$ for 2 $\min$, and $72^{\circ} \mathrm{C}$ for $6 \mathrm{~min}$ [ 40 cycles]). A $5-\mu 1$ aliquot of the initial one-sided PCR $(100 \mu$ l total) was used as a template for further PCR with the same gene-specific sense primer (P3) and one of the lambda arm primers (the sequence of the lambda arm primer is gcaagttcagcctggttaag; conditions were $95^{\circ} \mathrm{C}$ for $1.5 \mathrm{~min}, 50^{\circ} \mathrm{C}$, for $2 \mathrm{~min}$, and $72^{\circ} \mathrm{C}$ for $6 \mathrm{~min}[25$ cycles]). The products of this reaction were electrophoresed on a 1\% agarose gel, transferred to nitrocellulose, and probed with a $3^{\prime}$-end probe from the hMEF2C cDNA. The region of the gel which contained bands that hybridized to the probe were purified with GeneClean (Bio 101, La Jolla, Calif.) and used as a template for a final high-stringency PCR with a nested sense primer (ctgagttagtagtgcagacctg and the same lambda arm primer; $94^{\circ} \mathrm{C}, 1.5 \mathrm{~min} ; 65^{\circ} \mathrm{C}, 2 \mathrm{~min} ; 72^{\circ} \mathrm{C}$, 5 min [ 25 cycles]). This final reaction gave one abundant product which was then subcloned into pGEM $7 \mathrm{zf}(+)$ and sequenced. Overlap with the sequence at the $3^{\prime}$ end of the cDNAs confirmed that the cloned PCR product was the 3 ' end of the gene and confirmed the end of the open reading frame to be 30 aa downstream from that encoded by the cDNAs.

Immunofluorescence. For immunocytochemistry, $\mathrm{C} 2 \mathrm{C} 12$ cells (3) were seeded onto gelatin-coated glass coverslips at a density of $4 \times 10^{3}$ cells per $\mathrm{cm}^{2}$ and allowed to attach in mitogen-rich medium (Dulbecco's modified Eagle's medium plus $20 \%$ fetal calf serum). Myogenic differentiation was induced by changing the cells to Dulbecco's modified Eagle's medium containing 5\% horse serum and incubation at $37^{\circ} \mathrm{C}$ for 3 to 4 days. Primary cultures from postnatal rat visual cortex were prepared as described by Baughman et al. (2) and fixed after either 8 or 21 days in culture. COS cells were transfected as described above and fixed after 3 days in culture.
A

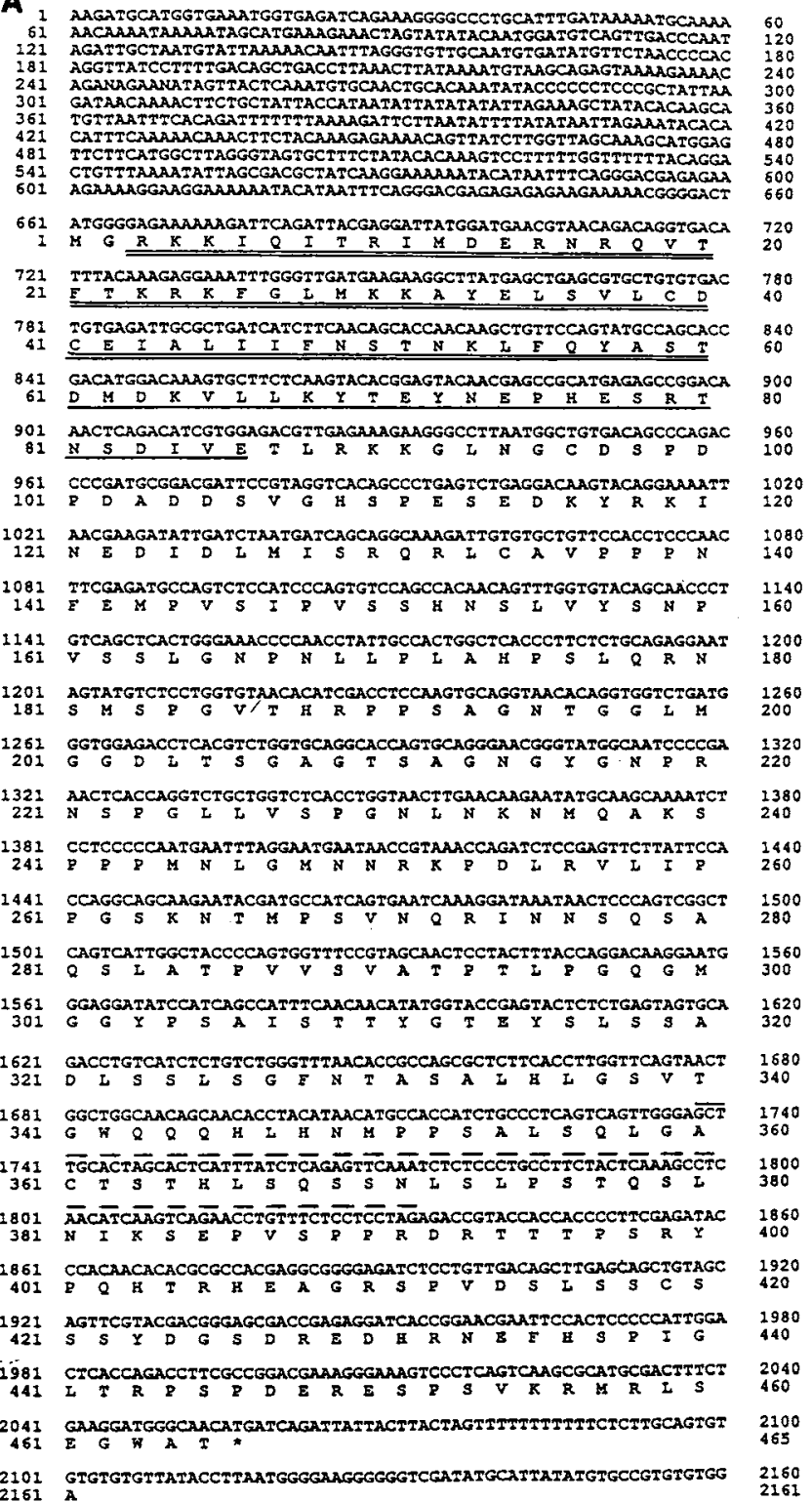

2101 GTGTGTGTTATACCTTAATGGGGAAGGGGGTCGATATGCATTATATGTGCCGTGTGTGG 2160

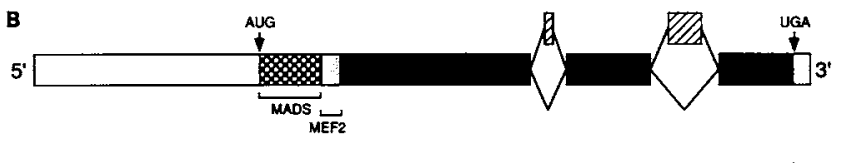

FIG. 1. hMEF2C as a member of the MEF2-related family of transcription factors. (A) Nucleotide (nt 1 to 2161) and predicted amino acid (aa 1 to 465 ) sequences of the hMEF2C cDNA. The double-underlined region indicates the putative MADS domain. The region downstream of the MADS domain which is necessary for sequence specificity of the MEF2-related factors is underlined. The alternatively spliced (96-nt) region at the $3^{\prime}$ end of the cDNAs is overlined with a dashed line. (B) Diagram of the various alternatively spliced hMEF2C gene products. Open box, untranslated sequence; checkered box, MADS domain; shaded box, MEF2 conserved regions; hatched boxes, hMEF2C alternative coding exons. 
Cells were washed once with phosphate-buffered saline (PBS), fixed for 10 to $20 \mathrm{~min}$ in $3.7 \%$ formalin in PBS, quenched for $10 \mathrm{~min}$ in $50 \mathrm{mM}$ glycine, and permeabilized with $0.25 \%$ Triton X-100 in PBS for 10 min (for rat cortical cultures, permeabilization was carried out for $5 \mathrm{~min}$ with $0.1 \%$ Triton X-100 in PBS). After being blocked for $10 \mathrm{~min}$ in $3 \%$ bovine serum albumin (BSA) in PBS, cells were stained for 60 min with diluted (1:800 and 1:4,000 dilutions gave the same results) polyclonal rabbit anti-hMEF2C antiserum which was raised against a TrpE fusion protein (aa 140 to 238). After extensive washes with $0.1 \%$ Nonidet $P-40$ in PBS, cells were incubated for $60 \mathrm{~min}$ with biotinylated donkey anti-rabbit immunoglobulins (Amersham; dilution, 1:200). The secondary antibody was followed by incubation for $30 \mathrm{~min}$ with streptavidin-Texas red (Amersham; dilution, 1:500) and washed with $0.1 \%$ Nonidet P-40 in PBS. All dilutions were made in $3 \%$ BSA in PBS, and all incubations were carried out at room temperature. For costaining with MF-20 monoclonal antibody (MAb), which specifically recognizes sarcomeric MHC, the biotinylated anti-rabbit immunoglobulins were diluted in MF-20 hybridoma tissue culture supernatant and incubated for $60 \mathrm{~min}$. This incubation was followed by 30 -min incubations with streptavidin-Texas red (1:500) and fluorescein-conjugated goat anti-mouse immunoglobulin G (IgG) (Boehringer Mannheim; dilution, 1:100). For costaining with the anti-neurofilament MAb (SMI 311; Sterneberger Monoclonals, Inc.; dilution, 1:1,000), the MAb was diluted together with the polyclonal rabbit anti-hMEF2C antiserum and incubated for $60 \mathrm{~min}$ followed by incubation with biotinylated donkey anti-rabbit immunoglobulins and fluorescein-conjugated goat anti-mouse $\operatorname{IgG}(1: 200$ and 1:100, respectively). The donkey anti-rabbit Ig was followed by addition of streptavidin-Texas red (1:500). After being washed in $0.1 \%$ Nonidet P-40 (in PBS), coverslips were mounted in $90 \%$ glycerol in PBS. Specimens were examined and photographed on Nikon Microphot-SA microscope or a Zeiss Axiovert 405M microscope equipped with phasecontrast and epifluorescence optics, with $40 x$ and $63 \times$ Planapochromat lenses. Pictures were recorded on Kodak Ektar 100 film.

Western blot (immunoblot) analysis. Whole-cell extracts were prepared from transiently transfected COS cells. Cells were washed three times in PBS, collected by centrifugation, and resuspended in 1 volume of ice-cold $2 \times$ lysis buffer $(20$ mM HEPES [ $N$-2-hydroxyethylpiperazine- $N^{\prime}$-2-ethanesulfonic acid]-KOH [pH 7.8], 0.6 M KCl, $1 \mathrm{mM}$ dithiothreitol, $20 \%$ glycerol, $2 \mathrm{mM}$ EDTA, $2-\mu \mathrm{g} / \mathrm{ml}$ leupeptin). Cells were lysed with three cycles of freezing and thawing. To remove the insoluble material, extracts were spun at 16,000 $\times g$ for $20 \mathrm{~min}$ at $4^{\circ} \mathrm{C}$. Protein concentration was determined with the modified Bradford assay (Bio-Rad).

For Western blot analysis, $5 \mu \mathrm{g}$ (total protein) of cDNAtransfected COS cell extract was electrophoresed by SDS$12 \%$ polyacrylamide gel electrophoresis (SDS-PAGE) and transferred by semidry blotting to Immobilin-P $(0.45 \mu \mathrm{m}$; Millipore) with $10 \mathrm{mM}$ CAPS (3-[cyclohexylamino]-1-propane-sulfonic acid) (pH 11.0)-10\% methanol. Filters were blocked for $1 \mathrm{~h}$ at $37^{\circ} \mathrm{C}$ with $25 \mathrm{mM}$ Tris-Cl (pH 8.0)-125 mM $\mathrm{NaCl}-0.05 \%$ Tween 20 , containing $4 \%$ nonfat dry milk. Incubations with total serum diluted $1 / 6,000$ (preimmune or immune serum) were performed for 8 to $12 \mathrm{~h}$ at $4^{\circ} \mathrm{C}$. Washes, incubations with secondary antibody, and visualization of the immune complexes were carried out as recommended by the manufacturer (Enhanced Chemiluminescence kit; Amersham).

\section{RESULTS}

hMEF2C cDNA clones and predicted protein sequence. A human adult skeletal muscle cDNA library was screened by low-stringency hybridization with a DNA probe which contains the MEF2 DNA-binding domain common to MEF2 and aMEF2, the first MEF2 factors isolated in our laboratory (52). Three cDNA clones which contained overlapping cDNAs with substantial homology to the DNA-binding domain of MEF2 (52) were chosen for further analysis (see Materials and Methods). The open reading frame encoded by these cDNAs is highly conserved in the DNA binding domain (74\% identity at the nucleotide level, $99 \%$ at the amino acid level) compared with the other MEF2 factors, but diverges outside of this conserved domain (Fig. 2A).

The longest cDNA insert $(1.9 \mathrm{~kb})$, designated hMEF2C, has one single long open reading frame, which extends to aa 435 as shown in Fig. 1A. The remainder of the coding sequence was obtained from another human skeletal muscle cDNA library (see Materials and Methods). The composite sequence (Fig. 1A) contains an in-frame AUG with upstream stop codons which fits the consensus as a strong translation initiation site (28). The hMEF2C cDNA encodes a 465-aa polypeptide (isoelectric point, 8.69 ), with a predicted molecular mass of $50.3 \mathrm{kDa}$. Alignment of the predicted amino acid sequences of hMEF2C and MEF2 reveals an overall identity of $66 \%$ (Fig. 2A), although they are almost identical at the $\mathbf{N}$ terminus ( 83 of 84 residues). The highly conserved $84-a a \mathrm{~N}$ terminus constitutes the DNA-binding domain of the MEF2 factors $(42,52)$. The amino-terminal part of this structural motif (aa 3 to 60 ) contains the MADS-box region (Fig. 2B). The carboxyl (C)-terminal end (aa 60 to 86) of this domain diverges from the other MADS factors but is highly conserved in the MEF2 family (Fig. 2B) (52). It has been previously shown for other members of this family of transcription factors that the DNA-binding function resides in a domain that includes the MADS homology region (37, 42, 52). However, at least for the MEF2 factors, the sequences located downstream from the MADS region are indispensable for DNA binding (52). These sequences are highly conserved among the MEF 2 factors and identify the gene family. For this reason, we have termed the sequences encompassing aa 60 to 86 the MEF2 domain. Indeed, differences in this region are responsible for different DNAbinding affinities among these factors (52).

After residue 86, hMEF2C and the other MEF2 sequences diverge considerably (Fig. 2A). The start of the diversity after residue 86 is also the point at which $M E F 2$ and an alternatively spliced isoform of MEF2 (aMEF2) diverge and corresponds to an intron-exon boundary (49a). In addition, hMEF $2 C$ lacks the glutamine- and proline-rich region which exists in the C-terminus of MEF2 (52), a region which is a known motif involved in transcription activation $(12,33)$. Two of the hMEF2C cDNA clones are identical, except that a 96-nt segment (nt 1737 to 1833) is absent in one of them and represents a bona fide splicing variant (Fig. 1B, referred to later as exon B). Scanning of the hMEF2C molecule for alternatively spliced forms by reverse transcription-PCR (RT-PCR) with a variety of paired primers identified that an additional alternate 24 -nt region, with the sequence SEDVDLLL inserted after aa 270 , is present in some mouse mRNA transcripts (Fig. 1B, referred to later as exon A). Therefore, there are at least two alternatively spliced regions in $\mathrm{hMEF} 2 \mathrm{C}$. We have cloned cDNAs encoding all of the four possible isoforms, indicating that they are produced in vivo (Fig. 1B). 


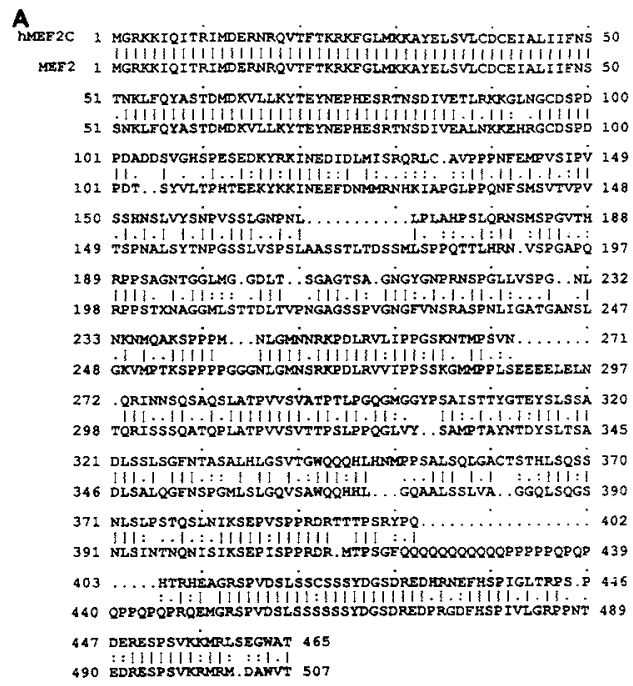

B
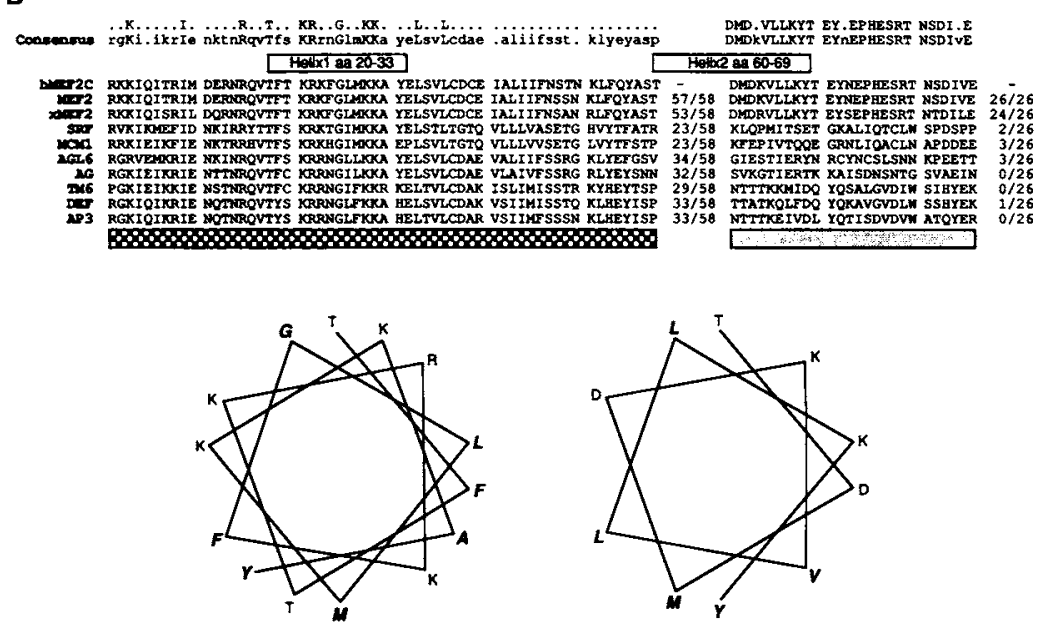

FIG. 2. hMEF2C sequence analysis. (A) Comparison of the predicted amino acid sequence of hMEF2C (present study) and MEF2 (52). I, identical amino acid; :, highly conservative substitution; ., conservative substitution. (B) Comparison of the MADS-MEF2 domain amino acid sequences from hMEF2C (present study), MEF2, xMEF2 (52), SRF (37), MCM1 (40), AGL6 (30), AG (51), TM6 (41), DEF (45), and AP3 (26). The MADS domain is the checkered sequence, and the MEF2-specific extension of the binding site corresponds to the shaded sequence. The overall identity between these factors is indicated at the right of each sequence. The absolutely conserved amino acids are indicated in capital letters in the consensus sequence, and conservative substitutions are indicated in lowercase letters. For the MADS domain, the consensus sequence is calculated for all of the factors. For the MEF2-specific domain, the consensus sequence is calculated just for the three MEF2-related factors. The two schematics show a cross-section of the two amino-terminal regions which contain predicted amphipathic alpha helices (aa 20 to 33 and aa 60 to 69, respectively). The amino-terminal end of helix1 begins at Thr-20 in the upper region of the diagram and rotates clockwise $100^{\circ}$ per residue to Tyr-33. Helix 2 begins at Thr- 60 in the upper region of the diagram and ends at Tyr- 69 in the lower region. The hydrophobic residues, which are in boldface, are clustered on one side of each alpha helix.

Analysis of the predicted amino acid secondary structure (20) of the hMEF2C molecule reveals that the binding domain contains a short alpha-helical region (aa 1 to 6) followed by a turn and an extended alpha helix (aa 20 to 48). The N-terminal part of this amphipathic alpha helix (aa 20 to 33 ) is highly hydrophilic and has a high surface probability, with the hydrophobic residues clustered on one side of the helix (Fig. 2B). The C-terminal part of the second helix (aa 34 to 48 ) is very hydrophobic, indicating that it is probably oriented to the interior of the molecule. The $\mathrm{N}$-terminal part (aa 60 to 69) of the MEF2-specific sequence (aa 60 to 86 ) is also predicted to be an amphipathic alpha helix (Fig. 2B) and is necessary for DNA binding $(42,52)$. The 8 -aa alternative peptide (exon $\mathrm{A}$ ) also has a predicted alpha-helical structure. The sequence has many potential sites for posttranslational modification. There are potential glycosylation sites at aa 49 , 275, and 371. Casein kinase II phosphorylation sites are located at aa 60 (in the MADS domain), 80 (in the MEF2 domain), 318, 404, 411, 421, 426, and 445 and also at aa 269 if the 8-aa alternate peptide (exon A) is present. Protein kinase $C$ phosphorylation sites are located at aa 22 and 51 (in the MADS domain), aa 87, 187, 426, and 453. Whether these sites are modified and their possible biological significance remain to be determined.

hMEF2C transcripts have a tissue-restricted pattern of expression and produce a brain-specific alternatively spliced isoform. Northern (RNA) blot analysis was carried out with cDNA derived from hMEF2C (nt 1591 to 1966; EcoRI-NdeI) to probe for corresponding transcripts in different human tissues. Transcripts were observed in poly $(\mathrm{A})^{+}$RNA isolated from brain and skeletal muscle but not in placenta, lung, liver, heart, and kidney tissue (Fig. 3A). Two transcripts of -7.5 and $\sim 4 \mathrm{~kb}$ were detected in both tissues; the longer transcript is abundant in both tissues, whereas the shorter ( - 4-kb) transcript is relatively more abundant in skeletal muscle than in brain tissue. A similar distribution pattern was observed with either a full-length cDNA probe or a probe from the $5^{\prime}$ end of the cDNA (nt 667 to 942; EcoRI-BglI; data not shown).

To discern whether the alternative regions in the hMEF2C cDNAs show any tissue specificity, we used RT-PCR to detect the 24-nt (exon A) and 96-nt (exon B) alternatively spliced regions in the mRNAs from various tissues. cDNAs were obtained by RT of mouse tissue mRNAs and subjected to PCR with two oligonucleotide primers (P1 and P2, Fig. $3 B$ ) known to span at least one intron. The resulting product was used as template for the amplification of the alternate exons, circumventing the possibility that PCR products are derived from contaminating DNA. PCR were carried out with nested primers which generate different-sized products, depending on the inclusion or exclusion of the 24-nt (exon A) or 96-nt (exon B) alternate exons. As illustrated in Fig. 3B, RT-PCR analysis revealed that the 96-bp insert (exon B) is present in all tissues which have an MEF2-like activity. Because of the high sensitivity of the PCR technique compared with Northern blotting, we were able to detect transcripts in heart atria and ventricles which were not detected by RNA blot analysis (Fig. 3A). However, the intriguing aspect of these data was that only the brain mRNA pool contained transcripts with the 24-nt alternate sequence (exon A). The restricted expression of this alternate exon indicates that brain tissue exclusively produces a larger hMEF2C protein that includes the peptide sequence SEDVDLLL. At present, we are investigating the possibility that this sequence is in the activator domain of the molecule and could mediate tissue-specific protein-protein interactions.

DNA-binding site specificity of hMEF2C isoforms. In order to investigate whether the $\mathrm{hMEF} 2 \mathrm{C}$ protein binds to the 

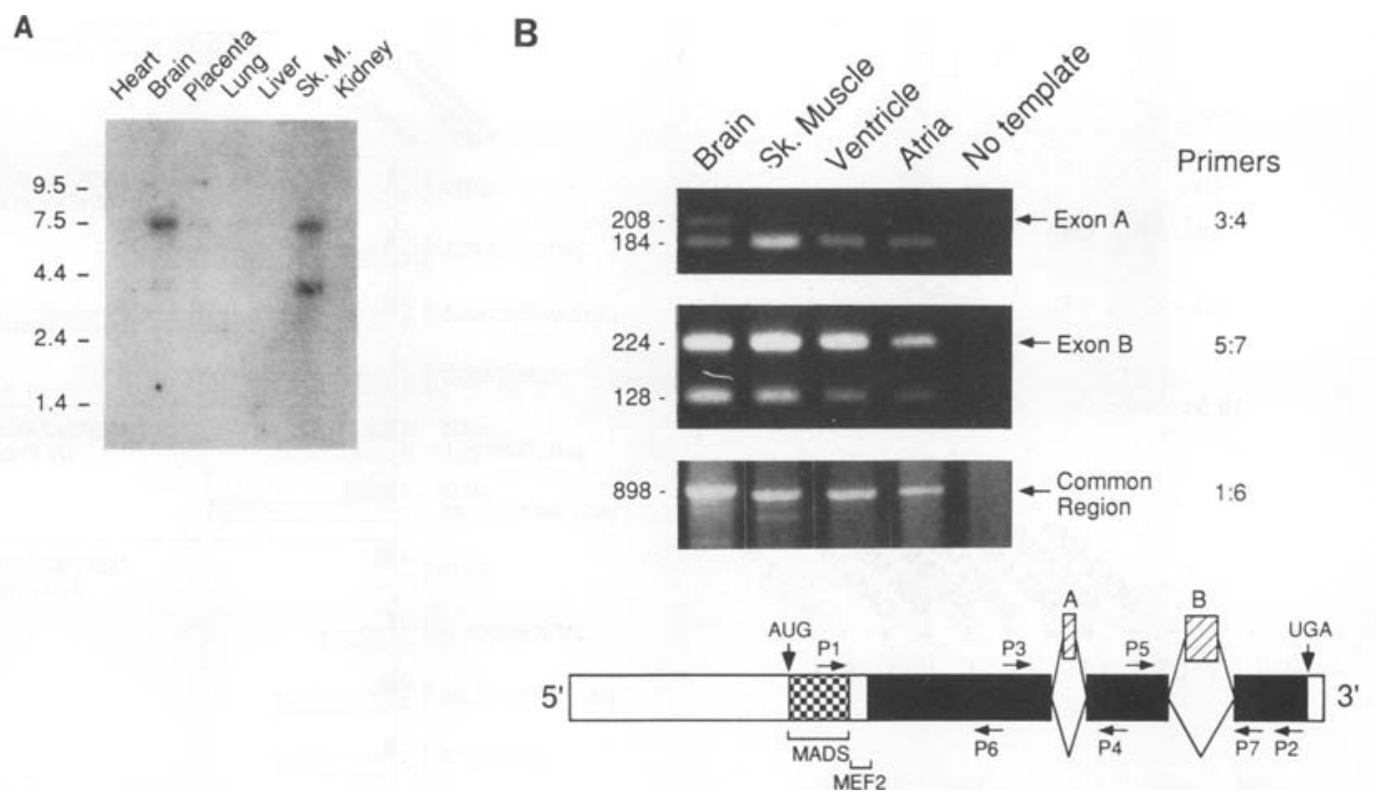

FIG. 3. Abundant expression of hMEF2C transcripts in skeletal muscle (Sk. M.) and brain. (A) Northern blot of poly(A) ${ }^{+}$RNAs from adult human tissues was hybridized at high stringency with a radiolabeled probe from the 3' end of hMEF2C (nt 1591 to 1966). The blot was stripped and hybridized with another probe from the cDNA (nt 667 to 942) which gave identical results. The blot has equivalent amounts of RNA per lane (data not shown). (B) Tissue specificity of the hMEF2C alternate exons. Reverse-transcribed mRNAs from several mouse adult tissue types were subjected to PCR to determine the expression of the hMEF2C alternative exons. The PCR product from the primer combination (P1-P2) was used as template for the amplification of the alternate regions. The primer combinations used to amplify each exon are designated on the gene schema. For the 24-nt exon (exon A), the possible products were $208 \mathrm{nt}$ (including exon A) or 184 nt (excluding exon A) (top panel; P3-P4 [3:4]). For the 96-nt exon (exon B) the possible products were $224 \mathrm{nt}$ (including exon B) or $128 \mathrm{nt}$ (excluding exon B) (middle panel; P5-P7 [5:7]). Finally, primers for a common region in the gene (P1-P6 [1:6]) were employed to generate an 898-nt fragment to assess whether general transcripts from the gene were present in these tissues. In all cases products were not obtained from non-reverse-transcribed RNAs.

MEF2 DNA-binding site, protein-DNA interactions were assessed with electrophoretic mobility shift assays. The binding of in vitro-translated hMEF2C (see Fig. 4A for in vitro-translated hMEF2C products) to a double-stranded oligodeoxyribonucleotide, comprising the previously characterized MCK enhancer MEF2 site $(14,22)$, was tested (Fig. 4B). The specificity of the protein-DNA complex observed between hMEF2C and the labelled MCK MEF2 site was determined by using various unlabelled synthetic oligonucleotides as competitors. The results of these experiments are consistent with the known specificity of the consensus binding site $\left[\mathrm{CTA}(\mathrm{AT})_{4} \mathrm{TAG}\right](14,42)$. The behavior of binding site mutants known to discriminate between MEF2 and ubiquitous factors (14) confirmed this conclusion. Mutant 4 which has a single base change at one of the variant positions in the consensus does bind and effectively inhibit the specific complex. Conversely, mutants 1 and 6 (52), which have mutations in the invariant region of the binding site, do not inhibit the specific complex, indicating that they are not bound by hMEF2C with appreciable affinity (Fig. 4B). As expected, the CArG-box-binding site, which is a high-affinity binding site for the MADS protein serum response factor (37), does not inhibit the binding. The brain creatine kinase enhancer MEF2-binding site, which fits the consensus for an MEF2 site, does inhibit the binding to the MEF2 site (Fig. 4B).

We tested whether the presence or absence of the peptide encoded by the 96-nt alternate region in the cDNAs would influence the DNA-binding affinity. However, there was no detectable difference between the DNA binding of in vitrotranslated proteins either with or without this region (Fig.
4B). In addition, a truncated version of the protein (aminoterminal aa 1 to 178 , truncated at the PstI site) retained its DNA-binding capacity (Fig. 4B). When the long and truncated forms were cotranslated, minimal amounts of a putative intermediary complex were detected, although the major complexes were composed of the long or truncated forms alone. Taken together, these observations demonstrate that hMEF2C and the other MEF2-related factors so far isolated (52) have similar in vitro DNA-binding specificities. This behavior is expected on the basis of the conserved nature of the DNA-binding domains between these factors ( 83 of 84 residues; Fig. $2 A$ and $B$ ).

hMEF2C isoforms activate transcription in an MEF2 sitedependent manner. To determine whether hMEF2C functions as an activator of transcription, the hMEF2C cDNAs in pMT2 eucaryotic expression vector (27) were cotransfected with various reporter constructs containing a heterologous minimal promoter and two copies of the MEF2 high-affinity binding site driving the bacterial CAT gene. All transfections were carried out in HeLa cells. The promoters used were (i) the basal MHCemb promoter (pE102 CAT [4]), (ii) the herpes simplex virus TK promoter (TK-CAT [32]), or (iii) the simian virus 40 early promoter (A10-CAT [34]). Each reporter construct was made with and without two copies of the MEF2-binding site fused upstream of the promoter. As shown in Fig. 5, trans-activation of the reporter constructs was dependent on the presence of the intact MEF2-binding sites and the transfection of hMEF2C or MEF2. It is interesting that the most potent trans-activation was observed with the muscle-specific promoter (MHCemb) (Fig. 5 ), which suggests differences among the transcription com- 
A

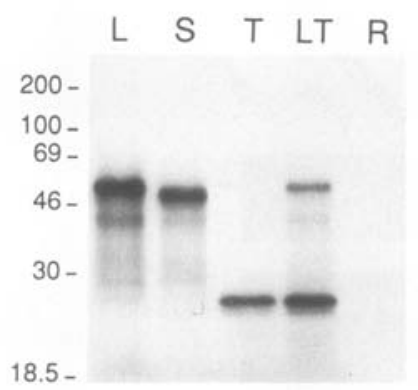

B

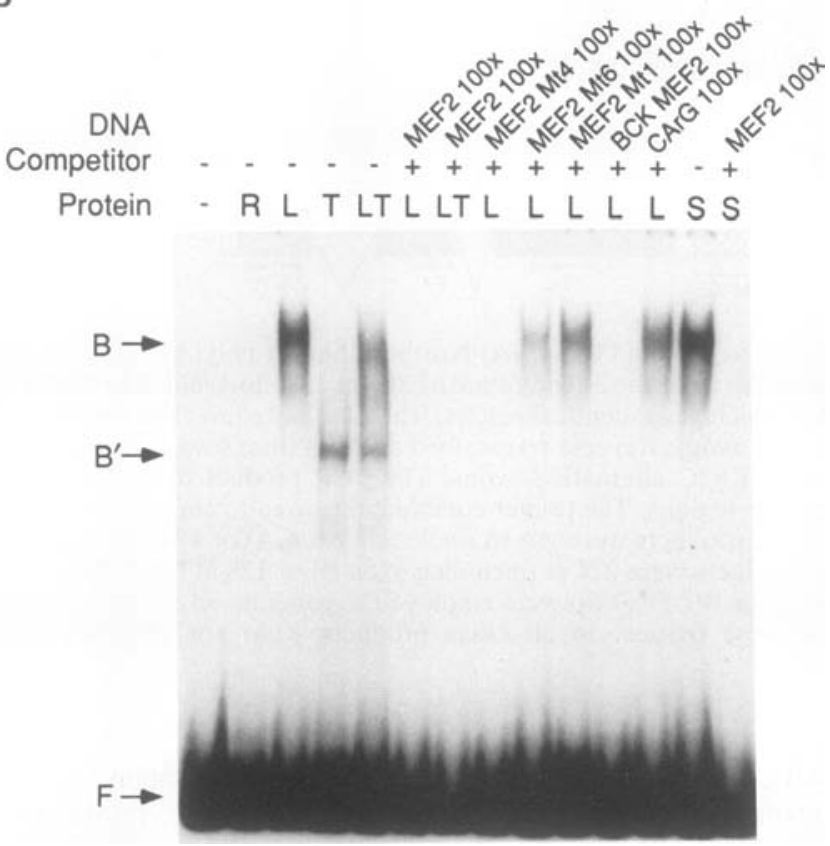

FIG. 4. Similarity of DNA-binding specificity of hMEF2C to those of the other MEF2-related gene family members. (A) In vitro-translated hMEF2C protein products from the cloned hMEF2C cDNAs used in DNA-binding assays. The different $\left[{ }^{35}\right.$ S $]$ methionine-labelled protein products illustrated after SDSPAGE and autoradiography are the full-length hMEF2C cDNA protein product $(\mathrm{L})$, the protein without the peptide encoded by the 96-nt alternate exon $(\mathrm{S})$, and a truncated product $(\mathrm{T})$ (see Materials and Methods). LT, products of a cotranslation of $L$ and $T ; R$, unprogrammed reticulocyte lysate. (B) Similarity of in vitro-translated hMEF2C DNA binding specificity to those of the other MEF2-related factors. In vitro-translated hMEF2C protein isoforms from the cloned hMEF2C cDNAs were assayed for DNA binding. Binding specificity was tested by using radiolabelled doublestranded MEF2-binding-site probe, in the absence or presence of a 100-fold molar excess of unlabeled competing oligonucleotide (specified at top). The hMEF2C isoforms containing the 96-nt alternate exon (L) and also excluding this region (S) and a truncated hMEF2C product $(\mathrm{T})$ were tested for DNA binding. In addition, the DNAbinding complexes formed from cotranslated $\mathrm{L}$ and $\mathrm{T}$ forms were assessed. Controls showing probe alone $(-)$ and probe bound in unprogrammed reticulocyte lysate $(R)$ are presented.

plexes assembled on different promoters. It has been reported that there is some promoter specificity of basal transcription factors (39). If this is the case, hMEF2C may prefer to interact with specific transcription factors assembled on the MHC emb promoter. Thus, the cellular context

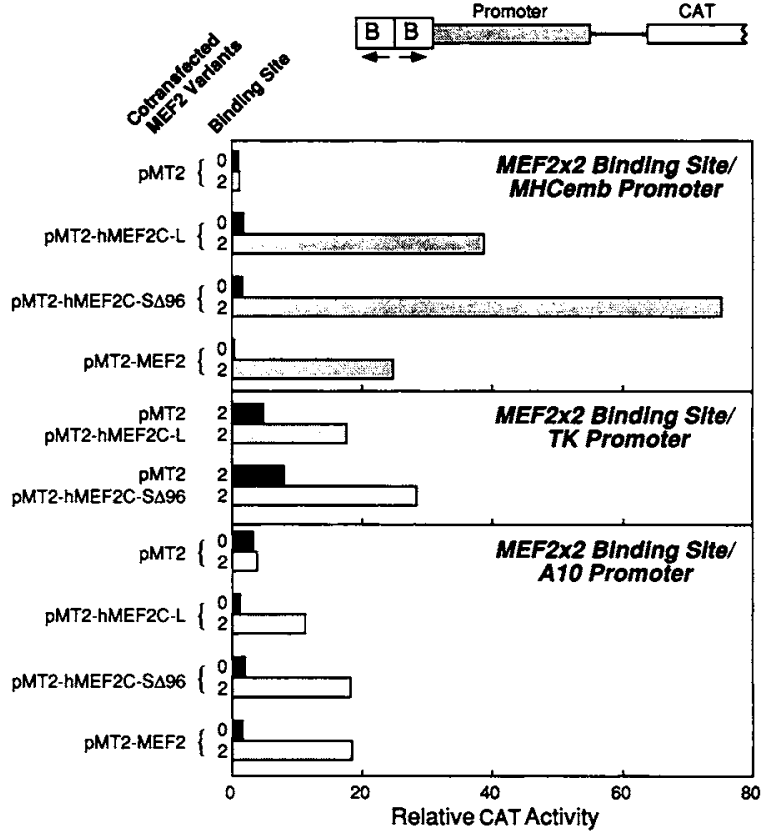

FIG. 5. Activation of transcription in an MEF2 site-dependent, promoter-independent manner by cloned hMEF2C. A schema for the various CAT reporter genes is illustrated. The promoters and duplicated binding sites (B) (with arrows indicating the antiparallel orientation) are specified. Panels show CAT activity in HeLa cells produced by cotransfection of one of the following cDNA expression constructs: pMT2-hMEF2C-L (the cDNA including the 96-nt alternate region), pMT2-hMEF2C-S $\Delta 96$ (the cDNA excluding the 96-nt alternate region), pMT2 control DNA, or pMT2-MEF2 derived from the first MEF2 gene isolated, with one of the following basal promoters: MHCemb, the herpes simplex virus TK promoter or the simian virus 40 promoter (A10). Each reporter construct was assembled and transfected with (2) and without (0) the MCK MEF2-binding sites attached to control for binding-site-independent activation of the reporter constructs. Each transfection experiment was repeated three times.

as well as the promoter element may be important for trans-activation by hMEF2C.

There is a precedent for differential trans-activational potency depending on the inclusion or exclusion of alternatively spliced exons in the activation domain of several transcription factors $(19,43)$. We therefore tested whether the presence or absence of the peptide sequence encoded by the two alternate regions altered the ability of the hMEF2C molecule to activate transcription. It has already been shown that the binding specificities of the two isoforms (with or without the 96-nt exon) are indistinguishable (Fig. 4B). We were also not able to detect any differences in trans-activational potencies by the proteins containing either exon $A$ or exon $B$. These data indicate that, under the conditions tested, all of the hMEF2C isoforms are sufficient to activate transcription in a sequence-specific manner. However, these results do not rule out more subtle differences between these factors that might be expressed in their native context.

Developmental regulation of hMEF2C expression in muscle. To determine whether the presence of the hMEF2C gene product is developmentally regulated, we performed indirect immunofluorescence analysis on $\mathrm{C} 2 \mathrm{C} 12$ myoblasts and myotubes with a polyclonal anti-hMEF2C antiserum raised against a fusion protein containing aa 140 to 238 (outside of 

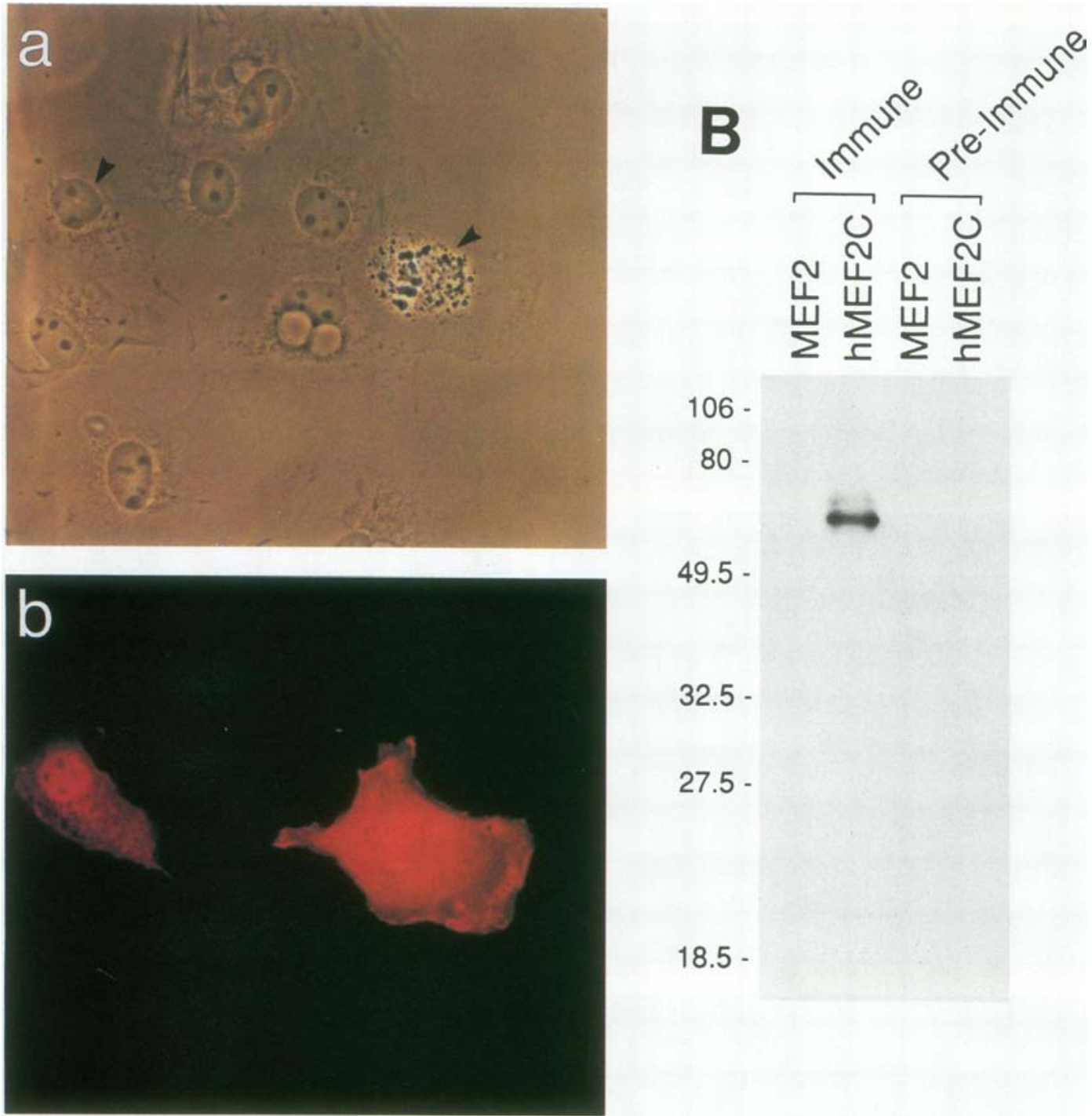

FIG. 6. Recognition of hMEF2C with high specificity by anti-hMEF2C antibody. (A) Phase-contrast (a) and corresponding immunofluorescence (b) micrographs of COS cells transiently transfected with hMEF2C cDNA. Cells were processed for immunofluorescence microscopy by using an hMEF2C-specific polyclonal antiserum. Arrowheads in phase-contrast panel (a) point to transfected cells. In panel $b$, nontransfected COS cells show negative staining and transfected ones exhibit different levels of hMEF2C expression. (B) Western blot analysis of extracts from COS cells transfected with either the hMEF2C or the MEF2 expression constructs. Western analysis was carried out as described in Materials and Methods.

the MEF2 conserved domain). To determine whether the antibody was specific for the hMEF2C protein, we carried out immunofluorescence and protein immunoblotting on COS cells transiently transfected with either hMEF2C or MEF2 expression constructs. Untransfected COS cells did not react with the hMEF2C antibody (Fig. 6A). Transfected cells exhibited different levels of hMEF2C expression, with lower levels localizing mostly to the nucleus and higher levels localizing to both the nuclear and cytoplasmic compartments (Fig. 6A). Immunoblots of COS cell extracts revealed that a single protein was recognized by the antihMEF2C antibody only in the cells which were transfected with the hMEF2C expression construct (Fig. 6B). No crossreactivity with extracts from cells transfected with the first MEF2-related factor (MEF2) was observed. Thus, the antibody appears to be specific for the hMEF2C isoforms.

We next examined the expression of hMEF2C in $\mathrm{C} 2 \mathrm{C} 12$ myogenic cells during their differentiation. We used double immunofluorescence with antibodies which specifically recognize all forms of sarcomeric MHC (1) (see Materials and Methods) to monitor the differentiation state of the cells. hMEF2C is not expressed in undifferentiated myoblasts, as determined by its absence in all the MHC-negative cells. hMEF2C protein was localized to the nuclei of differentiated multinucleated myotubes which were correspondingly stained for sarcomeric MHC (Fig. 7a, C through F). However, hMEF2C is not uniformly expressed in the differentiated cells. MHC-positive mononucleated cells were negative for hMEF2C (arrows on right side of Fig. 7a, C through F) as well as a subset of myotube nuclei located among positive ones. This pattern of expression, which was observed with different fixation protocols, together with the pattern of appearance of hMEF2C-positive cells, suggests that this factor is induced late in myotube formation and after the 

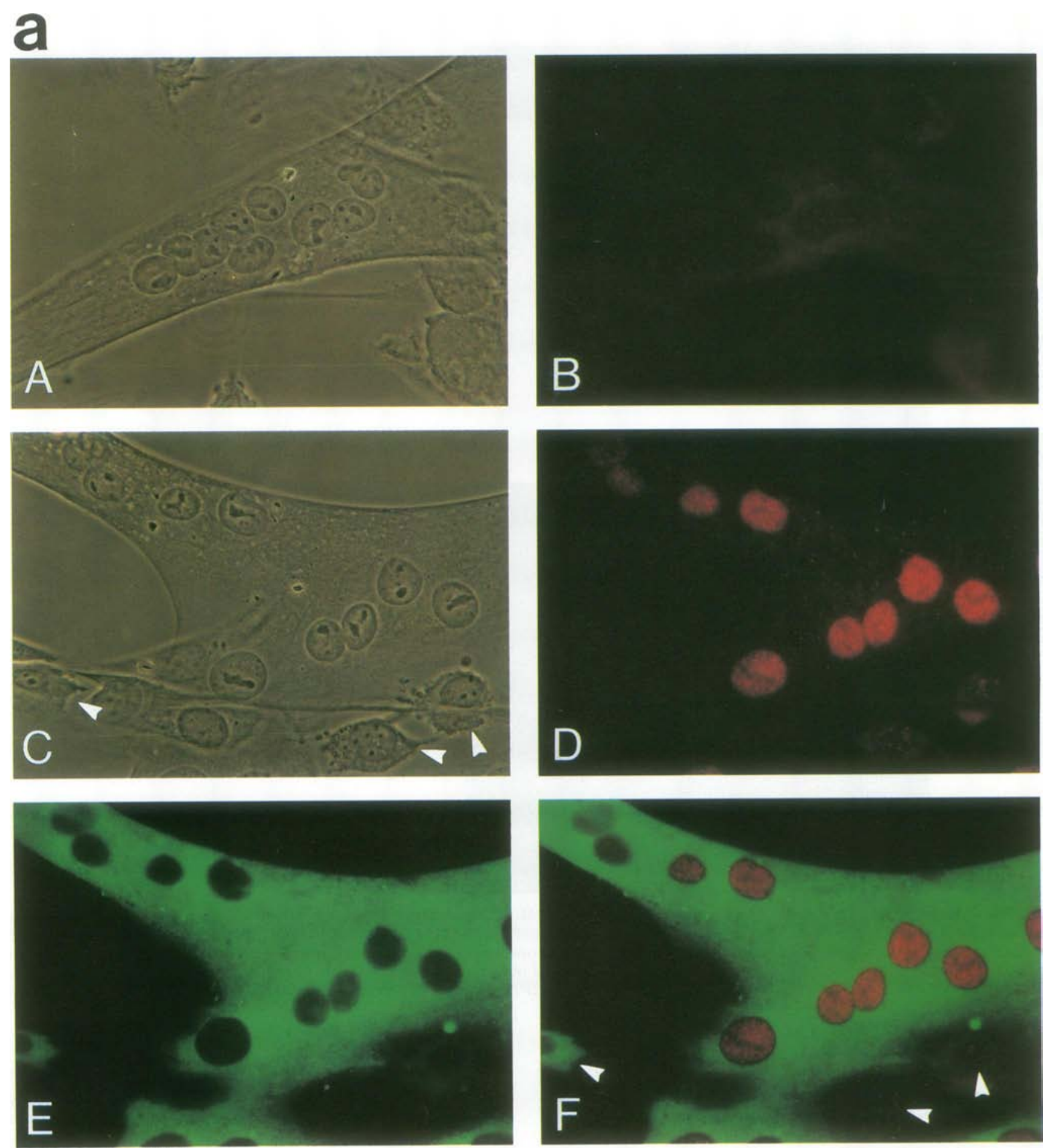

FIG. 7. Expression of hMEF2C protein in myotubes and in a subset of cortical neuronal cells. (a) Presence of hMEF2C in cultured murine muscle cells. $\mathrm{C} 2 \mathrm{C} 12$ myotube cultures were assayed for hMEF2C protein presence with a polyclonal hMEF2C-specific antiserum (red staining) and for sarcomeric MHC MF-20 MAb (green staining). As a control, panels A and B show the same field in phase-contrast and fluorescence microscopy with preimmune serum at the same dilution and exposure time as the specific hMEF2C antiserum. Panels $C$ through $F$ depict the same field with phase-contrast microscopy (C), hMEF2C-specific antiserum-staining nuclei in a myotube (D), MHC cytoplasmic staining (E), and a double exposure showing hMEF2C nuclear and MHC cytoplasmic staining ( $F$ ). Arrowheads in panels $C$ and $F$ point to unfused cells with (on the left) and without (on the right) MHC staining, which do not show any detectable hMEF2C protein. (b) Presence of hMEF2C in primary dissociated cell cultures of neural tissue. Rat neonatal visual cortical cultures ( 8 days, A through $\mathrm{D} ; 21$ days, $\mathrm{E}$ through $\mathrm{H}$ ) were assayed for the presence of hMEF2C protein by immunofluorescence with a polyclonal hMEF2C-specific antiserum (red staining) and for neurofilament by using the pan-neuronal MAb (green staining). Panels A through D depict the same field with phase-contrast microscopy (A), hMEF2C-specific antiserum-staining nuclei in neurons (B), neurofilament cytoplasmic staining (C), and a double exposure showing hMEF2C nuclear and neurofilament cytoplasmic staining (D). Panels $\mathrm{E}$ and $\mathrm{F}$ depict the same field with phase-contrast microscopy (E) and hMEF2C-specific antiserum-staining neuronal nuclei $(F)$. Arrowhead in panel $\mathrm{E}$ points to a neuron which is not stained with the hMEF2C-specific antibody. Panels $G$ and $H$ depict the same field with phase-contrast microscopy $(E)$ and MEF2-specific antiserum staining in neurons $(F)$. 
b
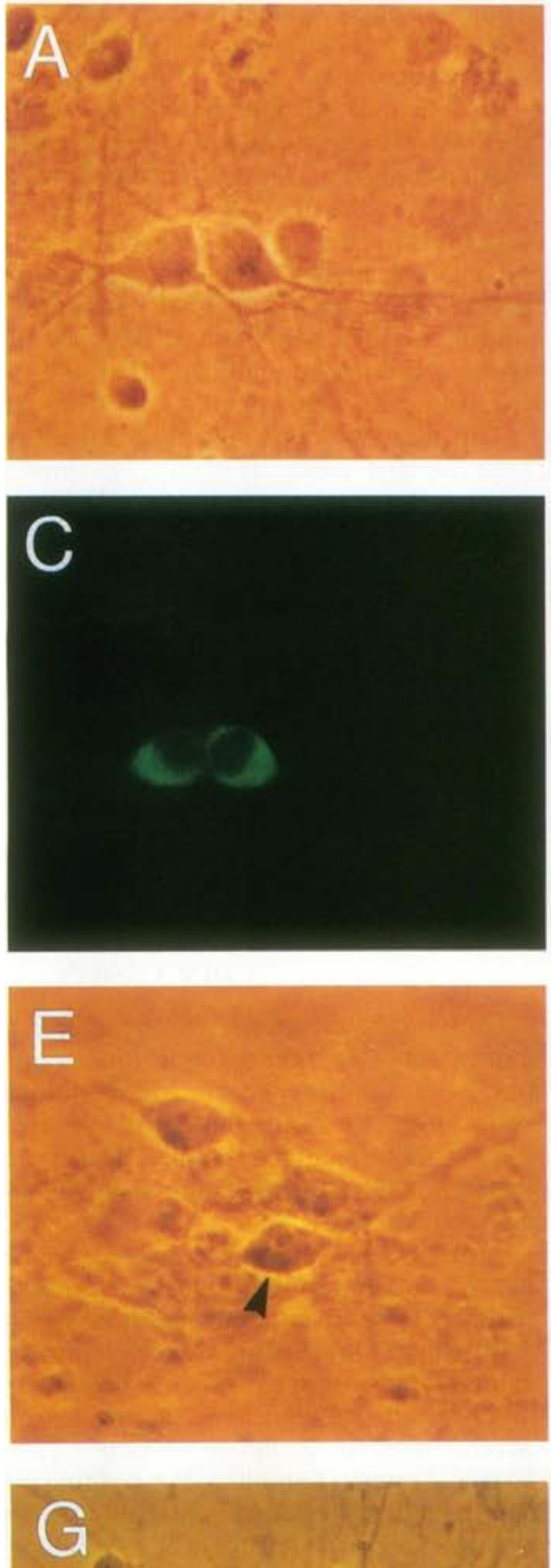

(4)
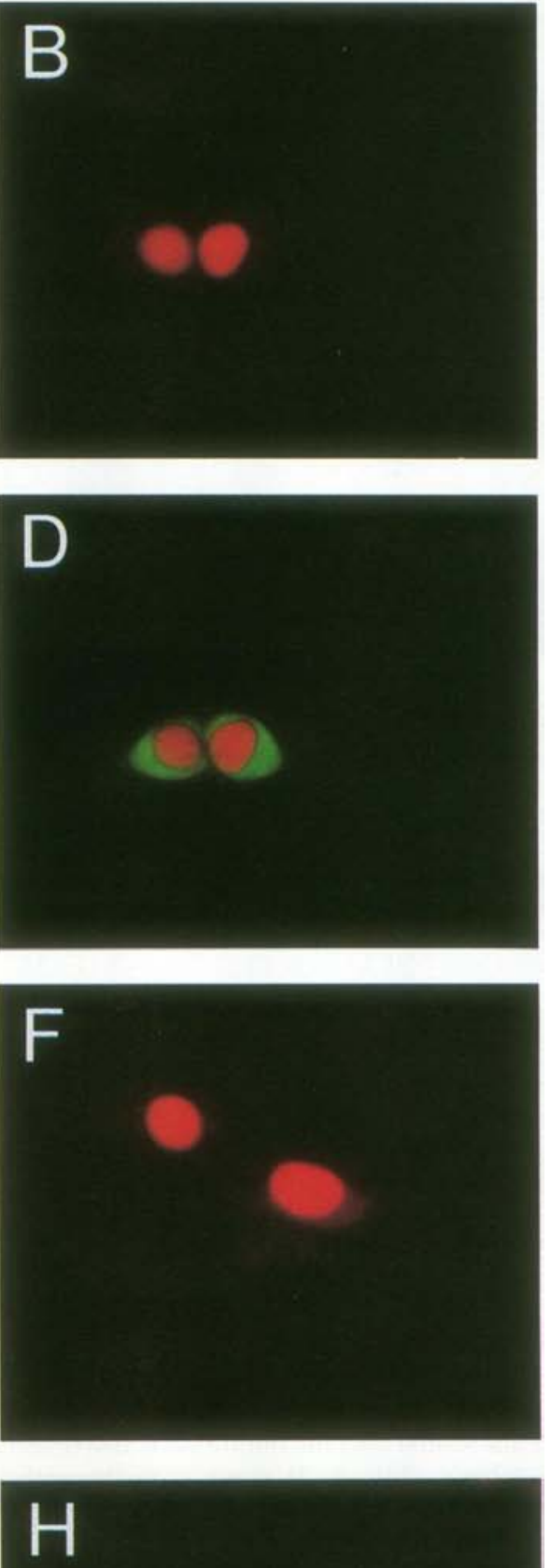

FIG. 7-Continued. 


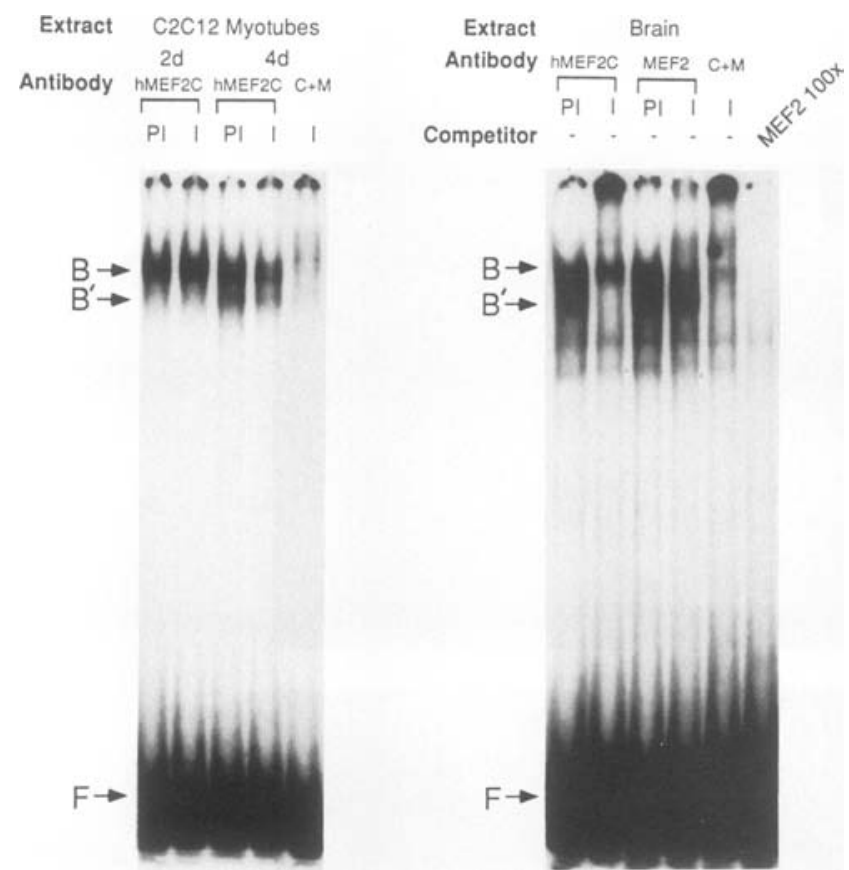

FIG. 8. MEF2 DNA-binding activity in muscle and brain extracts. Cell extracts from $\mathrm{C} 2 \mathrm{C} 12$ myotubes ( 2 and 4 days [2d and $4 d]$ after withdrawal of serum) and rat brain were used in gel-retardation assays in which the free probe $(F)$ was separated from the specifically bound probe $\left(\mathrm{B}^{\mathrm{B}}\right.$ or $\left.\mathrm{B}^{\prime}\right)$. Incubation of extracts and probe with the specific hMEF2C (C) or MEF2 (M) polyclonal antiserum was carried out with immune serum (I) along with preimmune control serum (PI) to test whether the endogenous MEF2 complex(es) could be disrupted or supershifted by the antibodies. Also, extracts were, in some cases, incubated with both antisera simultaneously $(C+M)$.

appearance of the related MEF2 factor. This was confirmed by using the antibodies in the analysis of the DNA-retardation complexes formed by cell extracts at different stages of differentiation. The anti-hMEF2C antibody causes a shift in the mobility of the complex formed by the in vitro-translated hMEF2C and the MEF2-binding site (data not shown). The anti-hMEF2C antibody, however, did not supershift the complexes formed by myotube cell extracts harvested 2 days after the induction of differentiation (Fig. 8). This band is supershifted by antibodies specific for the related MEF2 isoform (data not shown). However, 4-day-old myotube extracts produce an additional specific band that is disrupted by the hMEF2C antibody (Fig. 8, $\mathrm{B}^{\prime}$ ); we have recently generated an additional hMEF $2 \mathrm{C}$ antibody against a different part of the molecule which does supershift the myotube complex ( $\left.B^{\prime}\right)$ (data not shown), thus confirming the late onset of appearance of this transcription factor suggested by the immunofluorescence experiments (Fig. 7a).

hMEF2C is expressed in a subset of brain neurons. In view of the abundant expression of hMEF2C transcripts in brain tissue, we undertook to determine the pattern of expression of the protein in nerve cells. Gel-retardation studies revealed that there were two specific MEF2 complexes in brain extracts (Fig. 8). The complex with higher mobility $\left(\mathrm{B}^{\prime}\right)$ was completely supershifted by the hMEF2C antibody (Fig. 8). The complex with lower mobility (Fig. 8, B) was disrupted by the antibody raised against a peptide which is adjacent to the DNA-binding domain of the MEF2 protein (52) (Fig. 8). Incubation of the extract with both antibodies eliminated both complexes (Fig. 8), indicating that the MEF2 and hMEF2C proteins are major components of the brain MEF2 gel shift activity. In addition, the observation that each antibody supershifts only one of the complexes ( $\mathrm{B}$ or $\mathrm{B}^{\prime}$ ) argues strongly against heterodimer formation in vivo. However, these observations do not rule out the possibility that other proteins are involved in these complexes.

In situ hybridization studies have shown that hMEF2C mRNAs are expressed in a laminar pattern in cerebral cortex (data not shown). To further characterize the expression of hMEF2C in the brain, we determined whether the hMEF2C protein is present in cultured cortical cells. For this purpose, we made primary dissociated cell cultures from neonatal rat visual cortex and performed immunofluorescence analysis on these cells after 8 and 21 days in culture. The results of these experiments indicate that the hMEF2C protein is localized in neuronal cell nuclei (Fig. 7b, A through D).

It is also evident that only a subset of the neuronal cells express this factor (Fig. $7 \mathrm{~b}, \mathrm{E}$ through $\mathrm{F}$ ). In contrast, immunofluorescence with the MEF2-specific antibody revealed that all of the neuronal cells had positive staining for this factor (Fig. $7 \mathrm{~b}, \mathrm{G}$ through $\mathrm{H}$ ). Thus, there is a strong correspondence between the pattern of expression of hMEF2C in muscle and brain tissue. In both tissues, $\mathrm{hMEF} 2 \mathrm{C}$ expression is limited to a subset of differentiated cells, while the expression of the related MEF2 factors is detected in all the differentiated nuclei. The restricted pattern of hMEF2C expression in a subset of differentiated muscle nuclei is, at least in part, due to its late onset of appearance. More work will be required to determine whether this is also the case for the neuronal cells or whether its presence identifies a specific subset of neurons.

\section{DISCUSSION}

Convincing molecular evidence indicates that the cDNA clones reported here encode four proteins generated from one gene, all of which are MEF2-binding-site-specific transcription factors and, therefore, represent new members of the MEF2-related gene family. These proteins are produced through alternative splicing from a single gene we have named hMEF2C.

In contrast to the previously described members of this family, which are ubiquitously expressed at the RNA level, the mRNAs transcribed from the hMEF2C gene are detected at significant levels only in skeletal muscle and brain. Interestingly, one of the isoforms produced from this gene is highly brain specific and, therefore, might be involved in neuron-specific gene regulation. The products of the hMEF2C gene exhibit DNA-binding and trans-activation activities that are indistinguishable from those of previously isolated MEF2 factors (52). Immunolocalization studies demonstrated that $\mathrm{hMEF} 2 \mathrm{C}$ proteins are induced during late myogenesis, are not uniformly distributed among the myotube nuclei, and are limited to a subset of cortical neurons.

Tissue-specific expression of individual MEF2 genes is accomplished through different regulatory mechanisms. One of the confounding aspects of the MEF2 genes reported previously had been the necessity to reconcile the strict tissueand developmental-stage-specific expression of the protein, and therefore DNA-binding and trans-activation activity, with the ubiquitous distribution of the corresponding gene transcripts $(42,52)$. The available data indicate that posttranscriptional regulation is responsible for the functional pattern of expression of these genes. Most, if not all, of the regulatory events appear to occur at the pretranslational 
level, with tissue-specific patterns of pre-mRNA splicing playing a fundamental role (52).

Although not definitively shown by the results presented here, the tissue- and cell-specific pattern of expression of the hMEF2C gene, both at the mRNA and protein level, strongly suggests that this gene is regulated at the transcriptional level. In the case of the hMEF2C gene, posttranscriptional mechanisms appear to be limited to the production of different isoforms through alternative pre-mRNA splicing (8, 47 ), which is responsible for the production of the brainspecific isoform.

The evolutionary and/or physiological bases for the different regulatory modes used for the production of tissuespecific functional MEF2 protein isoforms are poorly understood at this time. However, their existence documents the presence of different upstream activators, transcription as well as splicing factors, for the different members of this gene family. Elucidation of these events is likely to reveal important clues for the understanding of the regulatory and developmental cues involved in the production of muscle and neuronal phenotypes.

MEF2 transcription factors participate in several developmental networks. It has been previously documented that MEF2 factors can be induced by the forced expression of MyoD and myogenin in certain non-muscle cells $(14,29,52)$. It is likely that this induction contributes significantly to the muscle-specific transcription induced by these myogenic factors. On the other hand, forced expression of different MEF2 expression constructs has failed to induce myogenic conversion of non-muscle cells despite their ability to produce a robust induction of muscle-specific gene transcription (52). These results suggest that in skeletal muscle, the MEF2 genes are downstream of the bHLH factors in the myogenic regulatory hierarchy. However, this interpretation is likely to be an oversimplification. First, different modes of activating the production of functional isoforms, alternative splicing and transcription, limit the potential for direct activation by the bHLH regulators to those genes that are transcriptionally regulated. Second, it is now clear that different MEF2 factors are expressed at different times in the myogenic program. While MEF2 isoforms appear very early in myogenesis and are uniformly expressed in all myotube nuclei (52), hMEF2C is expressed very late in myogenesis. This pattern of expression is reminiscent of that of the members of the MyoD gene family, which are expressed in a temporally and spatially restricted pattern during both embryogenesis (44) and in vitro myogenesis (6). These results raise the possibility that individual myogenic bHLH proteins are involved in the selective activation, directly or indirectly, of different MEF2 factors. Third, the existence of a functional MEF2 site in the myogenin promoter that is required for the correct expression of this gene (18) also complicates this serial view of a myogenic cascade in which factors are sequentially and unidirectionally induced. A complex network of auto- and cross-regulatory feedback loops is likely to be involved in the commitment and differentiation of skeletal muscle cells.

Even if the bHLH myogenic regulators are directly involved in the regulation of the MEF2 gene family, it is clear that other lineage-determining pathways must lead to their expression in non-muscle tissues. In this context, the findings that both skeletal muscles and a subset of cortical neurons express the hMEF2C gene strongly suggest that $\mathrm{hMEF} 2 \mathrm{C}$ also has an important role in neural gene regulation. Yet, this role and its target genes have not yet been identified. Moreover, it is not clear whether the subset of cortical neurons identified by the hMEF2C antibody represent a particular stage of neuronal maturation or a specific functional group. The fact that both muscle cells and neurons share many genes involved in membrane excitability and both permanently withdraw from the cell cycle during terminal differentiation might provide a rationale for the presence of shared tissue-specific transcription factors in the two cell types.

Complexity of the MEF2 family of transcription factors. Conservation of the MADS domain across a very broad evolutionary span denotes the importance of this structural motif in the homeotic fate, growth, and developmental properties of cells in different organisms $(11,40)$. The conserved sequences among this rapidly growing family of factors are mainly limited to the DNA-binding domain. It is now clear that many if not all of the members of this group participate in heterotypic protein-protein interactions by the recruitment of accessory factors that affect their DNAbinding and/or trans-activation activity $(23,48)$. In particular, their interactions with the homeodomain class of transcription factors, first documented between MCM1 and MAT alpha $2(48)$, has recently been highlighted by the interaction of serum response factor with the human homolog of the paired homeodomain protein (Phox) (23). Also, the serum response factor DNA-binding domain has been shown to interact with accessory factors that are unrelated to the homeodomain proteins $(15,46)$.

The existence of multiple isoforms of MEF2 factors that are tightly regulated in a cell- and developmentally specific manner suggests different functional roles for these isoforms. However, using cotransfection assays, we have been unable to demonstrate different functional properties among the hMEF2C isoforms, possibly because artificially high levels of transcription result from transfection assays, which may mask subtle differences in activation which occur in the normal cellular context. Preliminary observations indicate that the MEF2 factors interact with bHLH and other transcription factors. It remains to be determined whether the variable sequences outside of the DNA-binding domain are involved in defining specific heterotypic protein interactions. If this were the case, the combinatorial power of this family of factors to produce multiple patterns of gene transcription and/or cell specification would be substantially increased.

\section{ACKNOWLEDGMENTS}

This work was supported, in part, by grants from the National Institutes of Health and the Muscular Dystrophy Association.

We thank Jay Schneider for kindly providing mRNA for the RT-PCR experiments and David Welsh for the culturing of cortical tissue. Steve Mayer provided appreciated suggestions on the manuscript. We thank Roger E. Breitbart, Hanh Nguyen, and Vijak Mahdavi for helpful advice during the course of these studies. We also thank Tom O'Keefe and Roger McCarrick for the sequencing work, Shahla Movahedi for technical advice for the library screening, and Emily Flynn-McIntosh and Greta Knapschaeffer for the excellent graphics.

\section{REFERENCES}

1. Bader, D., T. Masaki, and D. A. Fischman. 1982. Biochemical analysis of myosin heavy chain during avian myogenesis in vivo and in vitro. J. Cell Biol. 95:763-770.

2. Baughman, R. W., J. E. Huettner, K. A. Jones, and A. AleemKhan. 1991. Cell culture of neocortex and basal forebrain from postnatal rats, p. 227-249. In G. Banker and K. Goslin (ed.), Culturing nerve cells. MIT Press, Cambridge, Mass.

3. Blau, H. M., C. P. Chiu, and C. Webster. 1983. Cytoplasmic activation of human nuclear genes in stable heterokaryons. Cell 
32:1171-1180.

4. Bouvagnet, P., E. E. Strehler, G. E. White, M. A. Strehler-Page, and B. Nadal-Ginard. 1987. Multiple positive and negative 5' regulatory elements control the cell-type-specific expression of the embryonic skeletal myosin heavy chain gene. Mol. Cell. Biol. 7:4377-4389.

5. Boxer, L. M., R. Prywes, R. G. Roeder, and L. Kedes. 1989. The sarcomeric actin CArg-binding factor is indistinguishable from the c-fos serum response factor. Mol. Cell. Biol. 9:515-522.

6. Braun, T., E. Bober, G. S. Buschausen-Denker, K. Grzeschik, and H. H. Arnold. 1989. Differential expression of myogenic determination genes in muscle cells: possible autoactivation by the Myf gene products. EMBO J. 8:3617-3625.

7. Braun, T., E. Tannich, G. Buschhausen-Denker, and $H$. $H$. Arnold. 1989. Promoter upstream elements of the chicken cardiac myosin light chain 2-A gene interact with trans-acting regulatory factors for muscle-specific transcription. Mol. Cell. Biol. 9:2513-2525.

8. Breitbart, R. E., A. Andreadis, and B. Nadal-Ginard. 1987. Alternative splicing: a ubiquitous mechanism for the generation of multiple protein isoforms from single genes. Annu. Rev. Biochem. 56:467-495.

9. Buskin, J. N., and S. D. Hauschka. 1989. Identification of a myocyte nuclear factor that binds to the muscle-specific enhancer of the muscle creatine kinase gene. Mol. Cell. Biol. 9:2627-2640.

10. Chomczynski, P., and N. Sacchi. 1987. Single-step method of RNA isolation by acid guanidium thiocyanate-phenol-chloroform extraction. Anal. Biochem. 162:156-159.

11. Coen, E. S., and E. M. Meyerowitz. 1991. The war of the whorls: genetic interaction controlling flower development. Nature (London) 353:31-37.

12. Courey, A. T., and R. Tjian. 1988. Analysis of SP1 in vivo reveals multiple transcriptional domains, including a novel glutamine rich activation motif. Cell 55:887-898.

13. Cserjesi, P., B. Lilly, L. Bryson, Y. Wang, D. A. Sassoon, and E. N. Olson. 1992. MHox: a mesodermally restricted homeodomain protein that binds an essential site in the muscle creatine kinase enhancer. Development 115:937-946.

14. Cserjesi, P., and E. N. Olson. 1991. Myogenin induces the myocyte-specific enhancer binding factor MEF-2 independently of other muscle-specific gene products. Mol. Cell. Biol. 11: $4854-4862$.

15. Dalton, S., and R. Treisman. 1992. Characterization of SAP-1, a protein recruited by serum response factor to the c-fos serum response element. Cell 68:597-612.

16. Davis, R. L., H. Weintraub, and A. B. Lassar. 1987. Expression of a single transfected cDNA converts fibroblasts to myoblasts. Cell 51:987-1000.

17. Devereux, J., P. Haeberli, and O. Smithies. 1984. A comprehensive set of sequence analysis programs for the VAX. Nucleic Acids Res. 12:387-395.

18. Edmondson, D. G., T. Cheng, P. Cserjesi, T. Chakraborty, and E. N. Olson. 1992. Analysis of the myogenin promoter reveals an indirect pathway for positive autoregulation mediated by the muscle-specific enhancer factor MEF-2. Mol. Cell. Biol. 12: 3665-3677.

19. Foulkes, N. S., and P. Sassone-Corsi. 1992. More is better: activators and repressors from the same gene. Cell 68:411-414.

20. Garnier, J., D. J. Osguthorpe, and B. Robson. 1978. Analysis of the accuracy and limitations of simple methods for predicting the secondary structure of globular proteins. J. Mol. Biol. 120:97-120.

21. Gilgenkrantz, H., J.-P. Hugnot, M. Lambert, P. Chafey, J. C. Kaplan, and A. Kahn. 1992. Positive and negative regulatory DNA elements including a CCArGG box are involved in the cell-type specific expression of the human muscle dystrophin gene. J. Biol. Chem. 267:10823-10830.

22. Gossett, L. A., D. J. Kelvin, E. A. Sternberg, and E. N. Olson. 1989. A new myocyte-specific enhancer-binding factor that recognizes a conserved element associated with multiple muscle-specific genes. Mol. Cell. Biol. 9:5022-5033.

23. Grueneberg, D. A., S. Natesan, C. Alexandre, and M. Z. Gilman.
1992. Human and Drosophila homeodomain proteins that enhance the DNA-binding activity of serum response factor. Science 257:1089-1095.

24. Horlick, R. A., G. M. Hobson, J. H. Patterson, M. T. Mitchell, and P. A. Benfield. 1990. Brain and muscle creatine kinase genes contain common TA-rich recognition protein-binding regulatory elements. Mol. Cell. Biol. 10:4826 4836 .

25. Ianello, R. C., J. H. Mar, and C. P. Ordahl. 1991. Characterization of a promoter element required for transcription in myocardial cells. J. Biol. Chem. 266:3309-3316.

26. Jack, T., L. L. Brockman, and E. M. Meyerowitz. 1992. The homeotic gene Apetala3 of Arabidopsis thaliana encodes a MADS box and is expressed in petals and stamens. Cell 68:683-697.

27. Kaufman, R. J., M. V. Davies, V. K. Pathak, and J. W. B. Hershey. 1989. The phosphorylation state of eucaryotic initiation factor 2 alters translational efficiency of specific mRNAs. Mol. Cell. Biol. 9:946-958.

28. Kozak, M. 1987. An analysis of $5^{\prime}$-noncoding sequences from 699 vertebrate messenger RNAs. Nucleic Acids Res. 15:81258148 .

29. Lassar, A. B., R. L. Davis, W. E. Wright, T. Kadesch, C. Murre, A. Voronova, D. Baltimore, and H. Weintraub. 1991. Functional activity of myogenic HLH proteins requires hetero-oligomerization with E12/E47 like proteins in vivo. Cell 66:305-315.

30. Ma, H., M. F. Yanofsky, and E. M. Meyerowitz. 1991. AGL1AGL6, an Arabidopsis gene family with similarity to floral homeotic and transcription factor genes. Genes Dev. 5:484-495.

31. Mar, J. H., and C. P. Ordahl. 1990. M-CAT binding factor, a novel trans-acting factor governing muscle-specific transcription. Mol. Cell. Biol. 10:4271-4283.

32. McKnight, S. J., and R. Kingsbury. 1982. Transcriptional control of a eukaryotic protein coding sequence. Science 217:316324.

33. Mermod, N., E. A. O'Neill, J. Kelly, and R. Tjian. 1989. The proline rich transcriptional activator of CTF/NF-1 is distinct from the replication and DNA binding domain. Cell 58:741-753.

34. Moreau, P., R. Hen, B. Wasylyk, R. Everett, M. P. Gaub, and P. Chambon. 1981. The SV40 base pair repeat has a striking effect on gene expression both in SV40 and other chimeric recombinants. Nucleic Acids Res. 9:6047-6052.

35. Muscat, G. E. O., S. Perry, H. Prentice, and L. Kedes. 1992. The human skeletal alpha-actin gene is regulated by a musclespecific enhancer that binds three nuclear factors. Gene Expression 2:111-126.

36. Nakatsuji, Y., K. Hidaka, S. Tsujino, Y. Yamamoto, T. Mukai, T. Yanagihari, T. Kishimoto, and S. Sakoda. 1992. A single MEF-2 site is a major positive regulatory element required for transcription of the muscle-specific subunit of the human phosphoglycerate mutase gene in skeletal and cardiac muscle cells. Mol. Cell. Biol. 12:4384-4390.

37. Norman, C., M. Runswick, R. Pollock, and R. Treisman. 1988. Isolation and properties of cDNA clones encoding SRF, a transcription factor that binds to the c-fos serum response element. Cell 55:989-1003.

38. Olson, E. N. 1990. MyoD family: a paradigm for development. Genes Dev. 4:1454-1461.

39. Parvin, J. D., H. T. M. Timmers, and P. A. Sharp. 1992. Promoter specificity of basal transcription factors. Cell 68:11351144.

40. Passmore, S., G. T. Maine, R. Elble, C. Christ, and B. K. Tye. 1988. A Saccharomyces cerevisiae protein involved in plasmid maintenance is necessary for mating of MATa cells. J. Mol. Biol. 204:593-606.

41. Pnueli, L., M. Abu-Abeid, D. Zamir, W. Nacken, Z. SchwarzSommer, and E. Lifschitz. 1991. The MADS box gene family in tomato: temporal expression during fioral development, conserved secondary structures and homology with homeotic genes from Antirrhinum and Arabidopsis. Plant J. 1:255-266.

42. Pollock, R., and R. Treisman. 1991. Human SRF-related proteins: DNA binding properties and potential regulatory targets. Genes Dev. 5:2327-2341.

43. Roman, C., L. Cohn, and K. Calame. 1991. A dominant negative 
form of transcription activator mTFE3 created by differential splicing. Science 254:94-97.

44. Sassoon, D., G. Lyons, W. E. Wright, V. Lin, A. Lassar, H. Weintraub, and M. Buckingham. 1992. Expression of two myogenic regulatory factors myogenin and MyoD1 during mouse embryogenesis. Nature (London) 341:303-307.

45. Schwarz-Sommer, Z., P. Huijser, W. Nacken, H. Saedler, and H. Sommer. 1990. Genetic control of flower development by homeotic genes in antirrhinum majus. Science 250:931-936.

46. Shaw, P. E., H. Schroter, and A. Nordheim. 1989. The ability of a ternary complex to form over the serum response element correlates with serum inducibility of the human c-Fos promoter. Cell 56:563-572.

47. Smith, C. W. J., J. G. Patton, and B. Nadal-Ginard. 1989. Alternative splicing in the control of gene expression. Annu. Rev. Genet. 23:527-577.

48. Smith, D. L., and A. D. Johnson. 1992. A molecular mechanism for combinatorial control in yeast: MCM1 protein sets the spacing and orientation of the homeodomains of an alpha two dimer. Cell 66:133-142.

49. Thompson, W. R., B. Nadal-Ginard, and V. Mahdavi. 1991. A myoD1 independent muscle specific enhancer controls the ex- pression of the beta-myosin heavy chain gene in skeletal and cardiac muscle cells. J. Biol. Chem. 266:22678-22688.

49a.Waldman, R. Personal communication.

50. Weintraub, H., R. Davis, S. Tapscott, M. Thayer, M. Krause, R. Benezra, T. K. Blackwell, D. Turner, R. Rupp, S. Hollenberg, Y. Zhuang, and A. Lassar. 1991. The myoD gene family: nodal point during specification of the muscle cell lineage. Science 251:761-766.

51. Yanofsky, M. F., H. Ma, J. L. Bowman, G. N. Drews, K. A. Feldmann, Meyerowitz, E. M. 1990. The protein encoded by the Arabidopsis homeotic gene agamous resembles transcription factors. Nature (London) 346:35-39.

52. Yu, Y.-T., R. E. Breitbart, L. B. Smoot, Y. Lee, V. Mahdavi, and B. Nadal-Ginard. 1992. Human myocyte-specific enhancer factor 2 (MEF2) comprises a group of tissue restricted MADS box transcription factors. Genes Dev. 6:1783-1798.

53. Zhu, H., A. V. Garcia, R. S. Ross, S. M. Evans, and K. R. Chien. 1991. A conserved 28-base-pair element (HF-1) in the rat cardiac myosin light-chain-2 gene confers cardiac-specific and $\alpha$-adrenergic-inducible expression in cultured neonatal rat myocardial cells. Mol. Cell. Biol. 11:2273-2281. 